\title{
A view from the cuckoo's nest: The value of teaching sociology in medical schools
}

\author{
Medical Humanities in the Middle East Conference \\ November 17-18, 2018 \\ Doha, Qatar
}

\section{Authors}

Adam H. Larson ${ }^{*}$

\section{Abstract}

In the late 1970s, medical schools across London sent representatives to participate in the University of London's Special Advisory Committee in Sociology as Applied to Medicine. Reflecting on the committee's work, Graham Scambler writes, "[it] gave voice to otherwise isolated cuckoos in the [medical school] nest". ' A number of innovative initiatives emerged from this collaboration, including an intercalated Bachelors of Science for medical students and the first textbook on sociology as applied to medicine, but sociology continues to hold a tenuous position in medical schools. Indeed, sociology remains a fringe element in medical education, despite the discipline's enduring fascination with health, illness, and medicine. This is particularly true in the Middle East and North Africa (MENA), where medical schools arose as colonial or nationalist projects committed to western biomedicine with a curriculum grounded in the basic sciences. However, in the West, this model is undergoing reforms to integrate the social sciences into the core curriculum. ${ }^{2}$ Medical educators aim for these reforms to develop new, more expansive ways of thinking and to improve professionalism and bedside skills.

This paper offers a "view from the cuckoo's nest" to advocate for the meaningful inclusion of sociology in contemporary medical curricula. Sociological methods and theories provide aspiring physicians with what Pierre Bourdieu called "a means of self-defense." In complex regions like the Middle East and North Africa, where ethnic, sectarian, and cultural tensions often lie just beneath the surface, physicians
'Weill Cornell Medicine-Qatar, Doha, Qatar

*Email: ahl2005@qatar-med.cornell.edu

Adam H. Larson iD https://orcid.org/0000-0002-0119-4789

\section{Cite this article as:}

Larson AH. A view from the cuckoo's nest: The value of teaching sociology in medical schools. In: Weber AS, Verjee MA, editors. Proceedings of the 1st International Conference on Medical Humanities in the Middle East [Internet]; 2018 Nov 17-18: Doha, Qatar: Innovations in Global Health Professions Education; 2019 March. p. 49-50. (Innovations in Global Health Professions Education; vol. 2019, spec. no.: 1). https://dx.doi. org/10.20421/ighpe2019.01.17

This is an open access article distributed under the terms of the Creative Commons Attribution license CC BY 4.0, which permits unrestricted use, distribution and reproduction in any medium, provided the original work is properly cited. 
require the intellectual resources to interpret and respond to their differently situated patients. Moreover, they face pressure to achieve results with limited resources, and sociology can equip them with critical insight into their work, and shed light on how these complex social forces shape professional practice. By moving sociology from the margins of medical education to the center, medical schools can transform how studentphysicians think about their patients, themselves, and their workplaces, and inspire a new generation of reflective practitioners. The paper considers important questions regarding the nature of medical curricula, discusses common educational problems that can be addressed through sociological methods, and applies the elements of Wear and Castellani's curricular vision to the Middle East context, focused on Qatar. ${ }^{3}$

For Wear and Castellani, ${ }^{3}$ the integration of sociology in medical schools involves epistemological values. They question the kinds of knowledge valued in and excluded from medical curricula, and contrast this with what students need to become physicians who can provide skilled, compassionate care. In so doing, they find that many medical schools, and therefore many students, conflate "valuable" medical knowledge with the basic sciences. While recognizing the sciences as a key component of medical education, Wear and Castellani ${ }^{3}$ suggest that more is required for students to become compassionate, communicative, and responsible professionals. They propose a full-spectrum curriculum emphasizing sociological consciousness, interdisciplinary perspective, and political and economic awareness of health care issues. They contend that such a curriculum would inculcate the "habits of mind and heart" 2 that student-physicians need to function successfully in contemporary health care settings (p. 226). For those in the Middle East and North Africa, who work in highly politicized and stratified contexts, sociology's critical tools can help them demystify their training and workplaces to foster system strengths while shoring up the weaknesses. As May and Clark maintain, the purpose and value of sociology in the medical curriculum is to "open up the work of the doctor and the practice of medicine to a more critical scrutiny, and to promote in students an understanding of those processes underlying the profound changes that will inevitably occur to the organization of health care and the practice of medicine". ${ }^{4}$

Conflicts of interest: None.

Funding sources: None.

\section{References}

1. Scambler G. Sociology in medical education. In: Brosnan C, Turner BS, editors. Handbook of the sociology of medical education. London, England: Routledge; 2009. p. 191-206.

2. Cooke M, Irby DM, O'Brien BC. Educating physicians: a call for reform of medical school and residency. San Francisco, CA: JosseyBass; 2010. 304 p.

3. Wear D, Castellani B. The development of professionalism: curriculum matters. Acad Med. 2000 Jun;75(6):602-11.

4. May D, Clark I. Cuckoo in the nest: some comments on the role of sociology in the undergraduate medical curriculum. Med Educ. 1980 Mar;14(2):105-12.

\section{About the author}

Dr. Adam Larson serves as Lecturer of English at Weill Cornell Medicine-Qatar where he teaches writing and coordinates the Writing Center. His interests include sociology, writing pedagogy, and the formation of professional knowledge. He holds a doctorate from King's College London, where his research explored factors influencing career choice in Qatar. 